\title{
Lefort: democracia e direitos humanos
}

Lefort: Democracy and Human Rights

\section{Tessa Moura Lacerda Universidade de São Paulo | São Paulo | Brasil}

\section{RESUMO}

O Estado moderno nasce, segundo Claude Lefort, quando ocorre um desintrincamento entre o poder e o direito. $\mathrm{O}$ poder passa por uma desincorporação e deixa de se identificar com o governante, sendo concebido, na modernidade, como um lugar vazio. Dessa maneira, não é mais o poder quem define o que é justo ou injusto e, ao contrário, o poder deve prestar contas ao direito. $\mathrm{O}$ direito, com a Declaração universal dos direitos do homem, ganha uma função simbólica. É isso que garante a possibilidade de reivindicação de direitos que não estão positivados nas leis escritas. A democracia se caracteriza, assim, pela afirmação do direito de criar direitos.

\section{PALAVRAS-CHAVE}

Democracia; Direitos humanos; Conflito; Luta política.

\begin{abstract}
The modern state is born, according to Claude Lefort, when there is a separation between power and law. The power goes through a disembodiment and stops identifying itself with the ruler, being conceived, in the modernity, like an empty place. In this way, it is no longer power that defines what is just or unjust and, on the contrary, power must be accountable to the law. The right, with the Universal Declaration of Human Rights, has a symbolic function. This is what guarantees the possibility of claiming rights that are not positive in the written laws. Democracy is thus characterized by the affirmation of the right to create rights.
\end{abstract}

\section{KEY WORDS}

Democracy; Human Rights; Conflict; Political Struggle. 


\section{A mutação moderna: um poder sem corpo}

O que é a democracia? Em lugar de "forma de governo" ou "regime de governo", Lefort usa a palavra "aventura" para definir a democracia: a expressão que ele emprega é "aventura democrática” (Lefort, 1986, p. 26). A democracia é uma aventura porque, acolhendo o conflito como essencialmente definidor do que caracteriza o político nas sociedades humanas, "se revela a sociedade histórica por excelência, sociedade que, na sua forma, acolhe e preserva a indeterminação, em contraste notável com o totalitarismo" (Ibid.). É a concepção de que a diferença, a heterogeneidade, a diversidade fazem parte da sociedade que leva a democracia a acolher, como essencial e legítimo, o conflito. Note-se: o conflito, não o confronto, não a violência.

A sociedade que se define pela violência é uma sociedade totalitária: o totalitarismo, diz Lefort, é "um regime no qual a violência estatal se abate sobre o conjunto da sociedade, um sistema de coerção generalizada, detalhada...” (Lefort, 20II, p. I4I). Essa violência se abate também e sobretudo porque se nega a divisão da sociedade, cria-se a ficção de uma sociedade indivisa e de um povo uno, em que não há lugar para a diferença e para a riqueza do conflito. Trata-se de uma sociedade que se representa como homogênea e, para isso, produz constantemente a representação de inimigos. Por meio da ideologia totalitária, o Terror, a perseguição de inimigos, se instaura como profilaxia que visa à integridade do corpo. O corpo político é aqui pensado como corpo orgânico. $\mathrm{O}$ totalitarismo instaura o dispositivo que exorciza qualquer ameaça, apagando os sinais de divisão social e expulsando a ideia de uma indeterminação histórica.

A indeterminação que caracteriza a democracia não é, segundo Lefort, da ordem dos fatos, porque está ancorada em uma mutação de ordem simbólica, que redefine a posição do poder. Trata-se de uma mutação do "político", do campo político, mutação que se dá nas fronteiras do Estado de direito. Historicamente, o Estado de direito, propiciou uma secularização de valores cristãos (de Cristo mediador, para o rei mediador) e uma reelaboração religiosa da herança romana. A "revolução política moderna" significa, por isso, a desaparição do "corpo do rei". Era no rei que se encarnava a comunidade e a justiça. No Antigo Regime, uma monarquia de tipo particular, com uma matriz teológico-política, o príncipe tinha uma potência soberana sobre o território e, ao mesmo tempo, era uma instância secular e um representante de Deus. Nessa monarquia, o poder estava incorporado na pessoa do príncipe. Mas, diz Lefort,

Isso não quer dizer que ele detinha um poder sem limites. O regime não era despótico. O príncipe era um mediador entre os homens e os deuses, ou antes, sob o efeito da secularização e da laicização da atividade 
política, um mediador entre os homens e as instâncias que figuravam a soberana Justiça e a soberana Razão. Sujeito às leis e acima das leis, ele condensava em seu corpo, ao mesmo tempo mortal e imortal, o princípio da geração e da ordem do reino. (Lefort, 1986, p. 27, grifo nosso).

O corpo, mortal e imortal, do rei, é o poder. Incorporado no príncipe, o poder dava corpo também à sociedade: "A sociedade do Antigo Regime representava para si sua unidade, sua identidade como a de um corpo - corpo que encontrava sua figuração no corpo do rei” (Lefort, 20II, p. I49). A imagem do corpo do rei, mortal e imortal, individual e coletivo, encontrou fundamento primeiro na figura de Cristo. Mesmo com as mudanças ocorridas ao longo do século XVIII e com o surgimento de novos modelos de sociabilidade, mantém-se a noção de uma unidade orgânica e mística do reino. A imagem de corpo místico, no qual os pequenos corpos dos indivíduos se organizam em um grande corpo imaginário, em Lefort, tem por referência claramente a leitura de Ernst Kantorowicz (cf. Ibid.); e não uma oposição à tradição filosófica que sugere o afastamento do corpo como algo negativo ou uma apropriação de esquemas conceituais lacanianos ${ }^{\mathrm{I}}$, a partir da ideia de corpo imaginário. Como mostrou Kantorowicz, analisando o duplo corpo do rei, um mortal e outro imortal, o rei se faz imortal pela imagem do corpo místico. Ora, a revolução democrática, "por muito tempo subterrânea, explode, quando o corpo do rei se encontra destruído, quando cai a cabeça do corpo político" (Ibid., p. I50).

A sociedade democrática, segundo Lefort, coloca em cheque a ideia de uma unidade orgânica, seja a unidade que havia no Antigo Regime, seja a unidade forjada nos regimes totalitários, sobretudo socialistas, nos quais o social e o Estado são soldados em um corpo único. ${ }^{2}$

A desaparição do corpo do rei na modernidade significa a desincorporação do poder, a desincorporação do direito e desincorporação da sociedade. O direito não terá mais uma essência e permite um debate sobre o que é e o que deve ser. Nesse sentido, a sociedade democrática inaugura uma história na qual os homens experimentam a indeterminação em sentido forte. Não temos um presente determinado por um futuro, mas o exercício constante da liberdade. Não temos uma ideia de sociedade que precisa ser progressivamente implantada, mas a possibilidade de criação contínua de novos direitos e novas demandas a partir da consciência dos direitos existentes.

I Como pareceu sugerir Vladimir Safatle, em debate na mesa "Democracia lefortiana" realizado no Congresso Internacional "Claude Lefort: a invenção democrática hoje", realizado em São Paulo entre os dias I3 e I6 de outubro de 2015.

2 Como mostrou Silvana Ramos, em debate na mesa "Democracia lefortiana” realizado no Congresso Internacional "Claude Lefort: a invenção democrática hoje”, realizado em São Paulo entre os dias I3 e I6 de outubro de 2015. 
Todavia, embora não seja pensada por meio de uma unidade harmônica, a sociedade democrática não deixa de buscar sua unidade: o Estado, o Povo, a Nação passam a ser entidades universais às quais todo indivíduo se encontra ligado - cabe aqui a pergunta pelo papel da ideologia no interior da democracia. ${ }^{3} \mathrm{~A}$ ideologia teria o papel de forjar uma unidade inexistente de fato na sociedade democrática? $?^{4}$ A modernidade irrompe quando a unidade que existia no Antigo Regime é quebrada. Mas a democracia corre sempre o risco de, buscando essa unidade perdida, encontrá-la em seu avesso, numa sociedade totalitária que opera pela figura do povo-Uno. Por isso, a busca por unidade na democracia nunca pode ser substituída por uma ocupação de fato do lugar vazio do poder, nem mesmo se essa ocupação for pensada a partir da figura do povo e da ideia de populismo. ${ }^{5} \mathrm{~A}$ democracia é uma sociedade inapreensível, indomesticável (cf. Ibid.). No momento em que o lugar vazio do poder é "ocupado" por uma figura empírica, então já não estamos mais na democracia, resvalamos para uma sociedade autoritária, incapaz de acolher o conflito, e que tem, na figura de seu líder, o fundamento para a ficção de uma sociedade indivisa. $\mathrm{O}$ totalitarismo, pelo menos o de versão socialista, diz Lefort, mantém uma relação com a democracia: "Derruba-a ao mesmo tempo que se apodera de seus traços e lhes traz um prolongamento fantástico" (Ibid., p. I49).

O "traço revolucionário e sem precedentes da democracia", diz Lefort, é o fato de que "o lugar do poder se torna um lugar vazio" (Lefort, 1986, p. 28) e, mais do que isso, deve permanecer sempre vazio. Os governantes não podem se apropriar, se incorporar ao poder. $\mathrm{O}$ exercício do poder, na democracia, está sujeito a um revezamento segundo regras, uma competição regrada. O que implica uma “institucionalização do conflito". Essa transformação do poder em lugar vazio, essa desincorporação do poder, quando não há mais uma unidade orgânica e mística do reino, significa que ocorre um desintrincamento entre poder e direito. Desintrincamento entre a esfera da lei, a esfera do poder e a esfera do saber. $\mathrm{O}$ poder não é mais o princípio de organização do corpo social, o direito e o saber se desprendem dele. Desintrincamento: palavra que visa mostrar que não há uma

3 Como sugerido por Renata Schevisbiski no debate mesa "Democracia lefortiana" realizado no Congresso Internacional "Claude Lefort: a invenção democrática hoje”, realizado em São Paulo entre os dias I3 e I6 de outubro de 2015.

4 Nesse sentido, parece não haver democracia sem ideologia. Essa questão foi objeto de debate com Silvana Ramos e Renata Schavisbiski na mesa "Democracia lefortiana", durante o Congresso Internacional "Claude Lefort: a invenção democrática hoje", realizado em São Paulo entre os dias I3 e I6 de outubro de 2015.

5 Como sugere Vladimir Safatle a partir da interpretação de Ernesto Laclau (debate na mesa "Democracia lefortiana" realizado no Congresso Internacional "Claude Lefort: a invenção democrática hoje”, realizado em São Paulo entre os dias I3 e I6 de outubro de 20I5). 
cisão entre poder e direito, mas uma separação que pressupõe sua articulação. $\mathrm{O}$ poder não pode ser estranho ao direito, se quisermos afirmar sua legitimidade. A mutação simbólica que caracteriza a revolução moderna significa que não é mais o poder que determina o direito, não é mais o poder que decide o que é justo ou injusto. Em lugar disso, o poder precisa prestar contas ao direito, precisa agir de acordo com a noção de direito se não quiser ser um poder que faz um uso ilegítimo da violência. Daí a função essencial da Declaração universal de direitos do homem $e$ do cidadão, como instância simbólica que "regula" o poder. O poder é objeto do direito, "doravante, a noção de direitos do homem dá sinal em direção a um foco indomável; nele o direito vem figurar vis-à-vis do poder uma exterioridade indelével." (Lefort, 20Irb, p. 72).

\section{Democracia e direitos humanos}

A relação umbilical entre democracia e a afirmação de direitos universais permite caracterizar a democracia por um "excesso". Uma sociedade democrática vai além da ideia de um Estado de direito, porque a função simbólica da Declaração universal de direitos faz com que a sociedade não esteja limitada à letra da lei, mas se afirme pelo direito de reivindicar novos direitos; esses direitos, muitas vezes, inexistentes na forma de leis positivas, mas que podem ser pensados porque há direitos universais declarados.

Quando não compreendemos essa relação profunda entre democracia de direitos universais, não vemos, propriamente, uma oposição entre uma sociedade totalitária e uma sociedade que reconhece os direitos do homem, atitude que "testemunha uma impotência em conceber os direitos do homem a não ser como direitos do indivíduo." (Ibid., p. 62). A crítica marxista das declarações de direitos do homem, como um instrumento ideológico da burguesia que eleva à categoria de homem o burguês, tem por fundamento, segundo Lefort, a ideia de que a realidade se define pelas relações de propriedade e poder, enquanto o direito é instalado no "santuário da moral, santuário que cada indivíduo carrega consigo." (Ibid.). Liberais e marxistas cometeriam o mesmo erro de leitura ao separarem o que depende da moralidade e o que depende da política. Sem abdicar da interpretação de Marx, mas propondo-se ir além dessa leitura, Lefort busca, na função simbólica da Declaração universal de direitos do homem, a possibilidade de ultrapassar seu caráter simplesmente ideológico para pensá-la como fundamento do jogo democrático que se caracteriza pelo direito de reivindicar direitos.

Para Lefort, há um vínculo fundamental entre a Declaração de direitos e a democracia. Mas essa relação, obviamente, não é pensada da mesma maneira que os liberais a pensam, porque estes, como os marxistas em sua crítica à Declaração de direitos, leem a sociedade como composta de indivíduos atomizados, e são cegos 
ao político, a um espaço social que se constitui separado e contra o poder. O que Lefort afirma é que a noção de direitos universais abre um espaço público que não existia antes, no qual os indivíduos são simultaneamente produto e instigadores (cf. Lefort, 199I, p. 47); o significado político dos direitos do homem é muito mais amplo do que satisfazer a interesses de uma classe, e isso Marx não soube ver. ${ }^{6}$

Há indeterminável nos direitos e isso é extremamente positivo, na leitura lefortiana. Esse indeterminável significa, em primeiro lugar, que os direitos humanos são um fundamento que não tem figura, por isso o poder não consegue se apoderar dele; em segundo lugar, há um excesso nos direitos humanos, de maneira que direitos adquiridos sustentam direitos novos; e, por fim, a Declaração não tem uma função histórica determinada (por exemplo, ascensão da burguesia).

Dessa maneira, é possível estabelecer uma oposição de direito em relação ao poder: "A partir do momento que os direitos do homem são postos como referência última, o direito estabelecido está destinado ao questionamento." (Lefort, 2orrb, p. 74). Logo, também a sociedade estabelecida está em questão, de modo que se uma classe tem os meios de explorar em proveito próprio os direitos, "esses meios permanecem expostos a uma oposição de direito." (Ibid., p. 75). Há uma separação entre poder e direito: com a desincorporação do poder, o lugar vazio deixado pelo rei com o nascimento da democracia moderna, não é mais o poder quem dita o direito, não há onipotência sobre o que é justo ou injusto. O Estado democrático excede algo que já havia no Estado de direito, a saber, a possibilidade de oposição ao poder com base no direito, porque experimenta direitos que ainda não foram incorporados: "desenvolveu-se assim sobre a base dos direitos do homem toda uma história que transgredia as fronteiras nas quais o Estado pretendia se definir, uma história que continua aberta." (Ibid.). Os novos direitos incorporam-se ao que foi considerado "constitutivo das liberdades públicas" (Lefort, I99I, p. 55).

\section{0 direito de exigir direitos: a dinâmica dos direitos humanos}

A nova relação com o político na democracia moderna deriva ou se torna efetiva e possível pela Declaração universal dos direitos do homem, menos pela letra do texto e mais pela eficácia simbólica da afirmação de direitos: "Esses direitos são um dos princípios geradores da democracia. Tais princípios não existem à maneira de instituições positivas [...]." (Lefort, 20Irb, p. 76). Essa eficácia simbólica, por sua vez, provém da adesão que lhes é dada, e essa depende da consciência dos direitos.

6 "Tal teoria não permite conceber o sentido da mutação histórica na qual o poder se encontra confinado a limites e o direito plenamente reconhecido em exterioridade ao poder: essa dupla aventura torna-se ilegível, simples sinal de ilusão." (Lefort, 20Irb, p. 7I). 
A consciência de que se tem o direito de exigir direitos é maior quando os Direitos do homem são declarados e o poder diz garanti-los. Por isso, há uma relação ambígua entre a consciência do direito e sua institucionalização: esta oculta os mecanismos de exercício dos direitos e ao mesmo tempo fornece apoio para sua consciência (mesmo no totalitarismo, os dissidentes se referiam às leis estabelecidas tendo por referência a Declaração universal de direitos, porque na sociedade moderna o poder não pode se privar dessa referência).

A dimensão simbólica do direito se manifesta ao mesmo tempo na irredutibilidade da consciência do direito a toda objetivação jurídica, o que significaria sua petrificação num corpo de leis, e na instauração de um registro público em que a escrita das leis - como escrita sem autor - só tem por guia o imperativo contínuo de um deciframento da sociedade por ela mesma. (Ibid., p. 76).

Nas lutas por direito na democracia, segundo Lefort, não se vê sinais de uma situação revolucionária. Essas lutas são avivadas "pela exigência de que aspirações de minorias ou de categorias particulares da população sejam socialmente reconhecidas." (Ibid., p. 79). Os modos de formação desses grupos e seus motivos são variados: podem ser produtos de circunstâncias (trabalhadores demitidos de uma empresa, por exemplo), podem formar-se por um sentimento de diferença em relação aos demais (homossexuais) ou por achar-se semelhante aos demais (os que perderam os meios de subsistência) etc. As lutas inspiradas pela noção dos direitos, porque nascem de núcleos diversos e às vezes até por conflitos conjunturais não tendem a fundir-se. A imagem do povo-Uno já não vale mais e tampouco se crê na realização do direito no real. Os exemplos de Lefort, em um texto de 1980, acentuam a particularidade das demandas e vão desde a luta das mulheres pela igualdade em relação aos homens, passando pelos homossexuais que se insurgem contra a repressão de que são objeto, até os camponeses de uma determinada região da França que se colocam contra a expropriação de suas terras em um período determinado (cf. Ibid., p. 77). O que aproxima essa heterogeneidade de reivindicações é a combinação aparentemente paradoxal da ideia de uma legitimidade e da representação de uma particularidade. Isso atesta a eficácia simbólica da noção de direitos. Como se o valor universal que o direito pode ter só pudesse aparecer por meio da particularidade. A reivindicação é sempre particular, mas ela se dá pelo reconhecimento de que se tem o direito de reivindicar, e esse direito está fundado na consciência dos direitos, que a Declaração permitiu na origem da democracia moderna.

A questão que se coloca, então, é por que algumas lutas conseguem se alçar à universalidade, quando reconhecidas como legítimas pela maioria da sociedade e 
outras não. Por que algumas lutas ganham a solidariedade da sociedade e outras passam desapercebidas, perdidas em sua particularidade? Quando um grupo de pessoas reivindica direitos no espaço público, essas pessoas "têm também consciência de serem vítimas, mais que de um dano, de um erro, enquanto sua fala não for ouvida" (Lefort, I99I, p. 55). Por que nem sempre essa fala é ouvida? Por que algumas lutas reivindicatórias conseguem atingir a consciência pública e outras não? Por que algumas reivindicaçôes não conseguem angariar a solidariedade da maioria da sociedade a ponto de alçar a aparente particularidade de sua reivindicação à universalidade?

Apesar dessa questão permanecer em aberto, o que Lefort aponta é que uma nova relação com o político se esboça nas lutas democráticas por direitos (cf. Lefort, 20IIb, p. 77). A primeira novidade no estilo e no caráter das reivindicaçōes é o fato de não esperarem uma solução global dos conflitos pela conquista ou destruição do poder estabelecido. Nem por isso o poder é ignorado. Mas não se trata mais de ver apenas o poder de Estado como fonte de mudança, nem de esperar "ouvidos complacentes" na cúpula do Estado para reivindicar novos direitos: "sob o impulso desses direitos a trama da sociedade política tende a modificar-se ou aparece cada vez mais como modificável” (Ibid., p. 77).

Por outro lado, se a luta por direitos não espera "ouvidos complacentes" do Estado, a reivindicação de um direito exige que o poder dê uma resposta que produza critérios de justo e injusto (universalidade) e não mais apenas de permitido e proibido (legalidade positiva). Sem essa resposta, o poder cai na coerção. Uma reivindicação por direitos exige do poder não mais apenas as leis, o que é proibido ou permitido, mas o fundamento dessas leis positivas, os critérios de justo e injusto: "a democracia convida-nos a substituir a noção de um regime regulado por leis, de um poder legítimo, pela noção de um regime fundado na legitimidade de um debate sobre o legitimo e o ilegitimo — debate necessariamente sem fiador e sem termo." (Lefort, I991, p. 57).

Lefort mostra, assim, a dimensão simbólica dos direitos do homem, dimensão, agora, constitutiva da sociedade política. De maneira que as críticas contra a aplicação de fato dos direitos humanos ou contra a representação de uma liberdade e de uma igualdade que valeria para todos independente de acidentes da vida social, na medida em permanecem no terreno dos fatos, não podem confundir simbólico e ideológico e não deveriam ignorar essa dimensão simbólica. É essa dimensão simbólica que mostra a lesão no corpo da sociedade quando se ataca os direitos do homem, seja em uma sociedade totalitária, seja em uma democracia.

A declaração universal de direitos serve, à sociedade, para um questionamento constante dos limites impostos pelo poder, de maneira que é possível caracterizar a democracia como a sociedade na qual temos o direito de exigir direitos. "A com- 
preensão democrática do direito implica a afirmação de uma fala — individual ou coletiva - que, sem encontrar sua garantia nas leis estabelecidas, ou na promessa de um monarca, faz valer sua autoridade, na expectativa de confirmação pública, em razão de um apelo à consciência pública." (Ibid., p. 55).

Ora, quando operários e empregados contestam a demissão em nome de seus direitos, camponeses resistem à expropriação em nome de seus direitos, mulheres exigem a igualdade em relação aos homens em nome de seus direitos, homossexuais se opõem à repressão de que são objeto em nome de seus direitos etc., esses direitos são afirmados graças à consciência do direito, consciência que é irredutível a uma objetivação jurídica, mas simultaneamente se apoia em princípios publicamente conhecidos (leis escritas): "uma das condições de êxito da reivindicação reside na convicção partilhada de que o novo direito está conforme à exigência de liberdade que atestam os direitos já em vigor" (Ibid., p. 54).

As contradições da democracia atual mostram que, de um lado, acentua-se as coerções, mas, de outro, propagam-se reivindicações que não são só resistência a essas coerções, "mas que testemunham um sentido difuso da justiça e da reciprocidade ou da injustiça e da ruptura da obrigação social.” (Lefort, 20Irb, p. 79). A democracia acolhe a luta permanente.

\section{Referências}

Lefort, Claude (1986). "La question de la démocratie", In Essais sur le politique, $X I X^{e}-X X^{e}$ siècles, Paris: Éditions du Seuil.

Lefort, Claude (199i). "Os direitos do homem e o Estado-providência", In Pensando o político, Rio de Janeiro: Paz e Terra.

Lefort, Claude (20II). "A imagem do corpo e o totalitarismo", In $A$ invenção democrática, Belo Horizonte: Autêntica Editora.

Lefort, Claude (20IIb). "Direitos do homem e política", In A invenção democrática, Belo Horizonte: Autêntica Editora. 